\title{
sciendo
}

CIVIL AND ENVIRONMENTAL ENGINEERING REPORTS

E-ISSN 2450-8594

CEER 2019; 29 (1): 018-027

DOI: $10.2478 /$ ceer-2019-0002

Original Research Article

\section{CONDITIONS FOR PHYSICAL MODELLING OF THE SPREAD OF CONTAMINANTS IN GROUNDWATER}

\author{
Andrzej ANISZEWSKI ${ }^{1}$, Rafał CIEPŁUCH, Norbert LASKOWSKI \\ West Pomeranian University of Technology, Szczecin, Poland
}

\begin{abstract}
The paper contains a review of dimensionless experimental dependencies determining the coefficient of transverse dispersion $\mathrm{D}_{\mathrm{y}}$. In the course of the dimensional analysis, dimensionless experimental dependencies describing the dispersion of pollutants in groundwater with hydraulic and physical parameters of soil in the case of steady and uniform groundwater motion were presented. The analysis allowed the determination of dimensionless practical relationships defining the dispersion factor in the perpendicular direction to the main flow direction.
\end{abstract}

Keywords: contaminants, groundwater, dispersion coefficient

\section{INTRODUCTION}

On the basis of the dimensional analysis, dimensionless experimental dependences between the dispersion coefficient values $\mathrm{D}_{\mathrm{y}}$ and the hydraulic and physical parameters of the soil: $\mathrm{k}, \mathrm{I}, \mathrm{d}_{10}$ in the case of spreading pollutants by steady and uniform groundwater motion are shown.

Definition:

$\mathrm{D}_{0}$ - the coefficient of molecular diffusion $\left[\mathrm{m}^{2} / \mathrm{s}\right]$,

\footnotetext{
${ }^{1}$ Corresponding author: West Pomeranian University of Technology, Faculty of Civil Engineering and Architecture, Piastów 50, 70-311 Szczecin, Poland, e-mail: andrzej.aniszewski@zut.edu.pl, tel. +48914494927
} 
$\mathrm{D}_{\mathrm{y}}$ - the coefficient of dispersion in the direction perpendicular to the main flow direction $\left[\mathrm{m}^{2} / \mathrm{s}\right]$,

$\mathrm{d}_{50}$ - the substitute diameter of the ground material [m],

$\mathrm{d}_{10}$ - the effective diameter of the ground material [m],

I - the groundwater table gradient [-],

$\mathrm{k}$ - the soil filtration coefficient $[\mathrm{m} / \mathrm{s}]$,

$\mathrm{v}$ - the filtration velocity of groundwater $[\mathrm{m} / \mathrm{s}]$,

$v$ - the coefficient of kinematic viscosity of water $\left[\mathrm{m}^{2} / \mathrm{s}\right]$,

Pr - the Prandtl number [-],

Pe - the dynamic Péclet number [-],

$\mathrm{Pe}_{\mathrm{m}}$ - the molekular Péclet number [-],

$\mathrm{Re}$ - the Reynolds number [-].

\section{A LITERATURE ANALYSIS FOR DIMENSIONLESS EXPERIMENTAL DEPENDENCIES OF DISPERSION COEFFICIENT DY}

It is widely accepted for determining the value of dispersion factor used the Prandtl number and Reynolds number in the form of general relationship:

$$
\operatorname{Pr}=\mathrm{a}_{1} \mathrm{Re}^{\mathrm{b}_{1}}
$$

The above relationship was widely verified in the range of laminar water movement $(\operatorname{Re} \leq 5)$ for soils whose substitute diameter $\mathrm{d}_{50} \geq 1 \mathrm{~mm}$. As a result, experimental values of coefficients were obtained: $a_{1} \in<0,11 ; 1,70>$, $\mathrm{b}_{1} \in<0,70 ; 1,10>$.

The research showed relatively large quantitative discrepancies between the coefficients $a_{1}$ and $b_{1}$, which was caused by various conditions in which the studies were performed [2].

When the scope of experimental studies was expended beyond the range of laminar motion $(5 \leq \operatorname{Re} \leq 380)$, the researchers found an increase in coefficients. For such groundwater flow conditions, the values of coefficients $a_{1}$ and $b_{1}$ increased respectively to 1.95 and 1.33 , which was explained by the increase in resistance to motion at the turbulent flow of groundwater in the porous medium. Using the Prandtl number and the Reynolds number, the size of the dispersion coefficients was determined by referring the values of the Reynolds number to the value of the specific filtration coefficient $\mathrm{k}$ 'in the form:

$$
\operatorname{Re}^{*}=\frac{\mathrm{v} \sqrt{\mathrm{k}^{\prime}}}{\mathrm{v}}
$$


where the specific coefficient k':

Based on the above relationships, it can be concluded that the dependence of $\operatorname{Pr}=f\left(\operatorname{Re}^{*}\right)$ can only be used in the filtration of liquids with essentially different physical properties of the contaminant solution.

Other researchers [5] have made the $\mathrm{D}_{\mathrm{y}}$ dispersion factor dependent on the following dimensionless products:

- the dynamic Péclet number $\mathrm{Pe}=\frac{\mathrm{vd} \mathrm{d}_{50}}{\mathrm{D}_{\mathrm{y}}}$,

- the molekular Péclet number $\mathrm{Pe}_{\mathrm{m}}=\frac{\mathrm{vd}_{50}}{\mathrm{D}_{0}}$,

- the Prandtl number,

- the Reynolds number .

In their research, among others A. E. Scheidegger [8] and P. G. Saffman [7] used the dynamic Péclet number and the molecular Péclet number in the form of the relationship $\mathrm{Pe}=\mathrm{f}\left(\mathrm{Pe}_{\mathrm{m}}\right)$ to determine the dispersion coefficient in the direction perpendicular to the main flow direction. The performed studies concerned the filtration velocity $\mathrm{v} \leq 10^{-6}$ and the values of Reynolds numbers $\mathrm{Re} \leq 10^{-4}$. Analyzing these studies, it can be concluded that the $\mathrm{D}_{\mathrm{y}}$ dispersion factor related to the Péclet number can be determined only in cases involving low filtration velocities. Under such flow conditions, molecular diffusion plays a significant role in the phenomenon of the spread of contaminants and the molecular diffusion coefficient $\mathrm{D}_{0}$ cannot be neglected.

Some authors used the dependence of the dynamic Péclet number and the Reynolds number in the form of the expression $P e=f(R e)$ to determine the coefficient of transverse dispersion. Experimental studies verifying this dependence were mainly conducted in the field of turbulent flow. Their summary was conducted by W. E. Ranz [6] and T. Baron [3], who found that for turbulent flow the value of dynamic Péclet number $\mathrm{Pe} \leq 11$, while for laminar flow $(\operatorname{Re} \leq 5)$, excluding inertial forces and resistance losses, the Péclet number may be smaller than its value in turbulent flow. Also other studies [1], [4] and our applied research confirmed this conclusion and showed that in the laminar flow range $(\operatorname{Re} \leq 1)$ the value of the Péclet number $\mathrm{Pe} \leq 4$.

Other approach is presented by authors [9] examining the value of the coefficient of transverse dispersion, taking into account dependance $\mathrm{Pe}=\mathrm{f}(\mathrm{Re})$ including the stratified flow caused by the high concentration of flowing contaminant. In the course of own research it was found that rate of contaminants concentration do not affect the difference in pollutants and groundwater solution. 
Summarizing experimental studies which determine value of $\mathrm{D}_{\mathrm{y}}$ factor based on the Péclet number and Reynolds number it can be stated that research were conducted mainly with large-grained or stony ground with a wide range of filtration velocity $\left(10^{-7} \leq \mathrm{v} \leq 10^{-1} \mathrm{~m} / \mathrm{s}\right)$. For both dependencies the Reynolds number value was referred to the substitute diameter of ground $\mathrm{d}_{50}$ and in laboratory tests grounds with wide range of granulation $\left(0,20 \geq d_{50} \geq 40,00 \mathrm{~mm}\right)$ were used. The dispersion coefficients were expressed in the form of dimensionless experimental dependencies taking into account:

- The Prandtl number and the Reynolds number,

- The Péclet number and the Reynolds number,

- The Péclet number and the molecular Péclet number.

The values of dispersion factors were related to the filtration velocity and the substitute diameter of the ground material $\mathrm{d}_{50}$.

\section{DIMENSIONLESS DEPENDENCIES SELECTION FOR DETERMINING DY COEFFICIENT}

Observations mentioned during the literature analysis justify the usefulness of performing laboratory test to determine the coefficient of transverse disperssion based on dimensionless relationships in a relatively little researched range of ground granulation diameters $\left(0,50 \geq \mathrm{d}_{50} \geq 1,00 \mathrm{~mm}\right)$. The $\mathrm{D}_{\mathrm{y}}$ factors were defined based on dimensionless relations taking into account:

- Prandtl number and Reynolds number in form $\operatorname{Pr}=f(R e)$ for grounds with diameter $\mathrm{d}_{50} \leq 1 \mathrm{~mm}$ instead of $\mathrm{d}_{50} \geq 1 \mathrm{~mm}$,

- Péclet number and Reynolds number in form $P e=f(R e)$ for laminar flow $(R e$ $\leq 5$ ) instead of turbulent flow.

In both types of dimensionless dependencies values of Reynolds number were referred to the size of the effective diameter $d_{10}$ instead of the substitute diameter $\mathrm{d}_{50}$ and the filtration coefficient $\mathrm{k}$ and the groundwater table gradient I instead of the filtration velocity $\mathrm{v}$. The justification of using the $\mathrm{k}, \mathrm{I}, \mathrm{d}_{10}$ dependencies was presented in detail in the previous paper [2].

In the researches the indicator with the same viscosity and density as groundwater was used, that is why the $\operatorname{Pr}=\mathrm{f}\left(\mathrm{Re}^{*}\right)$ dependence could not be applied in reference to $\mathrm{k}$ ' factor. Moreover, because of considering the spread of contaminants in a stream of groundwater for Reynolds numbers $R e \geq 10^{-3}$ the value of molecular diffusion $\mathrm{D}_{0}$ and relation $\mathrm{Pe}=\mathrm{f}\left(\mathrm{Pe}_{\mathrm{m}}\right)$ were omitted in researches. 


\section{ANALYSIS OF THE SPREAD OF CONTAMINANTS IN GROUNDWATER AND SELECTION OF COEFFICIENTS WHICH DESCRIBE THEM}

Analyzing the spread of contaminants in groundwater, seven parameters describing this phenomenon were identified:

- density of groundwater $\rho_{\mathrm{w}}$,

- filtration coefficient $\mathrm{k}$,

- difference in the height of water table $\Delta \mathrm{h}$ between the initial and final crosssection of the groundwater stream,

- the effective diameter of soil $\mathrm{d}_{10}$,

- length of the soil area L,

- the coefficient of kinematic viscosity of groundwater $v$,

- the coefficient of contaminants dispersion $D_{y}$.

In further considerations the fictitious forces, centrifugal forces and, additionally, the phenomenon of capillary infiltration occurring in the ground due to negligible effect of the phenomenon on the time of infiltration of pollutants were omitted, also by other researchers.

\section{DIMENSIONAL ANALYSIS}

The following function of spreading pollutants in groundwater has been assumed:

$$
f_{1}\left(D_{y}, k, \Delta h, L, d_{10}, v, \rho_{w}\right)=0
$$

In order to determine the objective function and to determine the scope of conducted research, a dimensional analysis was used. The symbols of Maxwell were used to describe the dimensions (length symbol L [m], mass symbol M [kg], time symbol $\mathrm{T}[\mathrm{s}])$.

The following is a matrix of dimensions created from exponents of dimension powers of accepted function arguments.

\begin{tabular}{c|ccccccc} 
& $\mathrm{D}_{\mathrm{y}}$ & $\mathrm{k}$ & $\Delta \mathrm{h}$ & $\mathrm{L}$ & $\mathrm{d}_{10}$ & 0 & $\rho_{\mathrm{w}}$ \\
$\mathrm{M}$ & 0 & 0 & 0 & 0 & 0 & 0 & 1 \\
$\mathrm{~L}$ & 2 & 1 & 1 & 1 & 1 & 2 & -3 \\
$\mathrm{~T}$ & -1 & -1 & 0 & 0 & 0 & -1 & 0
\end{tabular}

Selected three variables constituting the basis of the conducted analysis $\left(k, I, d_{10}\right)$ were checked for dimensional independence. The determinant value which is different from zero is a necessary condition and sufficient dimensional independence of the adopted variables. 


\begin{tabular}{l|ccc} 
& $\rho_{\mathrm{w}}$ & $\mathrm{d}_{10}$ & $\mathrm{k}$ \\
$\mathrm{M}$ & 1 & 0 & 0 \\
$\mathrm{~L}$ & -3 & 1 & 1 \\
$\mathrm{~T}$ & 0 & 0 & -1
\end{tabular} \mid$=-1 \neq 0$

Hence, the dimensionless product of $\pi_{\mathrm{i}}$ of the spread of contaminants function can be represented in the following form:

$$
\begin{gathered}
\pi_{1}=\rho_{w}^{a_{1}} d_{10}^{b_{1}} k^{c_{1}} D_{y} \\
\pi_{2}=\rho_{w}^{a_{2}} d_{10}^{b_{2}} k^{c_{2}} v \\
\pi_{3}=\rho_{w}^{a_{3}} d_{10}^{b_{3}} k^{c_{3}} L \\
\pi_{4}=\rho_{w}^{a_{4}} d_{10}^{b_{4}} k^{c_{4}} \Delta h
\end{gathered}
$$

Below are the values of the searched exponents $a_{i}, b_{i}, c_{i}$ for the product of dimensionless $\pi_{1}$.

$$
\left(\mathrm{M}^{1} \mathrm{~L}^{-3}\right) \mathrm{a}_{1}\left(\mathrm{~L}^{1}\right) \mathrm{b}_{1}\left(\mathrm{~L}^{1} \mathrm{~T}^{-1}\right) \mathrm{c}_{1} \mathrm{~L}^{2} \mathrm{~T}^{-1}=\mathrm{M}^{0} \mathrm{~L}^{0} \mathrm{~T}^{0}
$$

From the equation of exponents, we obtained $a_{i}=0, b_{i}=-1, c_{i}=-1$, thereby:

$$
\pi_{1}=\frac{D_{y}}{d_{10} k}
$$

Form of the remaining dimensionless products is as follows:

$$
\begin{aligned}
& \pi_{2}=\frac{v}{d_{10} \mathrm{k}}, \\
& \pi_{3}=\frac{\mathrm{L}}{\mathrm{d}_{10}}, \\
& \pi_{4}=\frac{\Delta \mathrm{h}}{\mathrm{d}_{10}} .
\end{aligned}
$$

According to $\pi$ 's claim, the pre-established pollution spreading function can thus be replaced by:

$$
f_{1}\left(D_{y}, k, \Delta h, L, d_{10}, v, \rho_{w}\right)=\Psi_{1}\left(\pi_{1}, \pi_{2}, \pi_{3}, \pi_{4}\right),
$$

where $\Psi_{1}\left(\pi_{1}, \pi_{2}, \pi_{3}, \pi_{4}\right)$ is a numerical function of the $\pi_{\mathrm{i}}$ dimensionless arguments. 
The analysis allows the dependence of the $\mathrm{D}_{\mathrm{y}}$ dispersion factor on four dimensionless $\pi_{\mathrm{i}}$ products. The phenomenon of pollutant spread in groundwater depends on the four dimensionless numbers obtained, as demonstrated by the dimensional analysis. In the experimental studies carried out, close interrelationships between the dimensionless products obtained were found.

\section{DIMENSIONLESS PRACTICAL DEPENDENCIES OF DISPERSION COEFFICIENT DY}

On the basis of the analysis of obtained dimensionless products and the review of dimensionless experimental dependencies, the following dependences were selected in terms of their practical application.

- including Prandtl number and Reynolds number in form $\operatorname{Pr}=f(R e)$,

- including Péclet number and Reynolds number in form $P e=f(R e)$.

To obtain the dependence of $\operatorname{Pr}=f(\operatorname{Re})$ the products of $\pi_{\mathrm{i}}$ were transformed in the form [10]:

$$
\begin{gathered}
\pi_{1}^{*}=\frac{\pi_{2}}{\pi_{1}}=\frac{v}{D_{y}}=\operatorname{Pr} \\
\pi_{2}^{*}=\frac{\pi_{4}}{\pi_{2} \pi_{3}}=\frac{\mathrm{k} \mathrm{I} \mathrm{d} \mathrm{d}_{10}}{\mathrm{v}}=\operatorname{Re}
\end{gathered}
$$

while in order to obtain the dependence of $P e=f(R e)$, the products of $\pi_{\mathrm{i}}$ were transformed into the following forms:

$$
\begin{aligned}
& \pi_{1}^{* *}=\frac{\pi_{4}}{\pi_{1} \pi_{3}}=\frac{\mathrm{k} \mathrm{I} \mathrm{d}_{10}}{\mathrm{D}_{\mathrm{y}}}=\mathrm{Pe} \\
& \pi_{2}^{*}=\frac{\pi_{4}}{\pi_{2} \pi_{3}}=\frac{\mathrm{k} \mathrm{I} \mathrm{d} \mathrm{d}_{10}}{\mathrm{v}}=\mathrm{Re}
\end{aligned}
$$

The range of applied values of dimensionless numbers $\pi_{1}^{*}, \pi_{1}^{* *}, \pi_{2}^{*}$ is as follows:

$$
\begin{gathered}
8,00 \leq \pi_{1} * \leq 39,71 \\
0,65 \leq \pi_{1} * * 3,43 \\
0,02 \leq \pi_{2}^{*} \leq 0,43
\end{gathered}
$$

Number $\pi_{2}^{*}=\operatorname{Re}$ contains hydraulic and physical parameters of the ground $\left(\mathrm{k}, \mathrm{I}, \mathrm{d}_{10}\right)$ used also in the dimension dependence determining the dispersion factor 
$\mathrm{D}_{\mathrm{y}}$ [2]. The values of $\pi_{2}{ }^{*}$ number corresponded to the range of laminar motion $(\operatorname{Re} \leq 5)$.

To determine the dependence of $\pi_{1}^{*}=\mathrm{f}\left(\pi_{2}^{*}\right)$ an equation was developed in the form:

$$
\pi_{1}^{*}=\mathrm{B}_{1} \pi_{2}^{* \mathrm{C}_{1}}
$$

while in order to determine the dependence of $\pi_{1} * *=\mathrm{f}\left(\pi_{2}^{*}\right)$, the equation appears in the form:

$$
\pi_{1}^{* *}=\mathrm{B}_{2} \pi_{2}^{* \mathrm{C}_{2}}
$$

The values of dimensionless numbers together with the coefficients $B_{1}, C_{1}, B_{2}$ and $\mathrm{C}_{2}$ (according to the least squares method) as well as the squares of deviations $\Delta^{2}$ and the mean squared deviations include table no. 1 according to the relationships (11) and (12).

Table 1. The values of dimensionless numbers according to the relationships (11) and (12).

\begin{tabular}{|c|c|c|c|c|c|c|}
\hline No. & $\pi_{1}{ }^{*}$ & $\pi_{1}{ }^{*}$ eq. & $\Delta^{2}$ & $\pi_{1} * *$ & $\pi_{1} * *$ eq. & $\Delta^{2}$ \\
\hline 1 & 2 & 3 & 4 & 5 & 6 & 7 \\
\hline 1 & 39,7082 & 38,4439 & 1,5984 & 3,4315 & 3,2284 & 1,5784 \\
3 & 33,3459 & 33,7773 & 0,1861 & 3,1524 & 3,0010 & 0,2461 \\
4 & 26,8641 & 29,3252 & 6,0570 & 2,8558 & 2,8057 & 0,7016 \\
5 & 26,8335 & 26,5647 & 0,0722 & 2,7597 & 2,6420 & 0,1714 \\
6 & 23,3801 & 21,7759 & 2,5734 & 2,4279 & 2,7963 & 2,5464 \\
7 & 22,0752 & 23,6132 & 0,2894 & 2,2236 & 2,4265 & 1,0031 \\
8 & 21,5923 & 25,0936 & 7,6634 & 2,1753 & 2,1201 & 0,0894 \\
9 & 20,0453 & 19,5197 & 4,2981 & 2,1716 & 2,3018 & 1,5264 \\
10 & 19,8652 & 21,1282 & 1,5951 & 1,9098 & 1,8441 & 3,2663 \\
11 & 18,6653 & 21,2893 & 6,8853 & 1,8427 & 1,9482 & 2,0652 \\
12 & 16,8196 & 18,6167 & 3,2295 & 1,8224 & 1,8711 & 0,9416 \\
13 & 16,8056 & 16,6693 & 0,0185 & 1,7383 & 1,7662 & 0,0427 \\
14 & 16,6494 & 16,3404 & 0,0954 & 1,6536 & 1,6387 & 0,1723 \\
15 & 16,5675 & 16,9828 & 0,1724 & 1,6257 & 1,7042 & 0,6461 \\
16 & 16,1534 & 17,9093 & 3,0831 & 1,6045 & 1,5464 & 0,4772 \\
17 & 15,6031 & 15,2651 & 0,1142 & 1,5694 & 1,6100 & 0,5227 \\
18 & 15,3376 & 16,3021 & 0,9302 & 1,4953 & 1,4991 & 0,0431 \\
19 & 14,7401 & 15,8518 & 1,2358 & 1,4512 & 1,4130 & 0,1793 \\
20 & 14,3036 & 14,7747 & 0,2219 & 1,4067 & 1,4298 & 0,0964 \\
21 & 14,0397 & 14,3813 & 0,1166 & 1,3842 & 1,3032 & 0,9445 \\
22 & 13,0554 & 13,4088 & 0,1248 & 1,3781 & 1,4259 & 1,0332 \\
23 & 12,9577 & 13,6959 & 0,5419 & 1,3622 & 1,2637 & 1,1331 \\
\hline
\end{tabular}




\begin{tabular}{|c|c|c|c|c|c|c|}
\hline 24 & 12,1268 & 12,5435 & 0,1726 & 1,2869 & 1,2729 & 0,0391 \\
\hline 25 & 11,7835 & 12,4345 & 0,4238 & 1,2090 & 1,2759 & 0,7733 \\
\hline 26 & 11,6382 & 12,0676 & 0,1843 & 1,1861 & 1,1481 & 1,0428 \\
\hline 27 & 10,9282 & 11,4130 & 0,2350 & 1,1657 & 1,1635 & 0,0095 \\
\hline 28 & 10,5770 & 10,7742 & 0,0388 & 1,0704 & 1,0936 & 0,2982 \\
\hline 29 & 10,1813 & 10,5779 & 0,1572 & 0,9962 & 0,9858 & 0,0378 \\
\hline 30 & 9,5364 & 9,8352 & 0,0892 & 0,9816 & 1,0306 & 0,9193 \\
\hline 31 & 9,2497 & 9,1885 & 0,0037 & 0,9173 & 0,8832 & 0,0970 \\
\hline 32 & 9,0140 & 9,4060 & 0,1536 & 0,8546 & 0,8968 & 0,9495 \\
\hline 33 & 8,7412 & 8,5361 & 0,0420 & 0,7545 & 0,7830 & 1,0016 \\
\hline 34 & 8,6135 & 8,0625 & 0,3036 & 0,7069 & 0,6920 & 0,0058 \\
\hline 35 & 8,0000 & 7,4437 & 0,3094 & 0,6510 & 0,6182 & 0,9091 \\
\hline & \multicolumn{3}{|c|}{$\begin{aligned} \mathrm{B}_{1} & =4,8634 \\
\mathrm{C}_{1} & =-0,5029 \\
\Delta & =1,1338\end{aligned}$} & \multicolumn{3}{|c|}{$\begin{aligned} \mathrm{B}_{1} & =4,4433 \\
\mathrm{C}_{1} & =0,4707 \\
\Delta & =0,9298\end{aligned}$} \\
\hline
\end{tabular}

\section{SUMMARY, CONCLUSIONS AND INDICATIONS FOR FURTHER RESEARCH}

In the course of the conducted analysis, it was proved that the coefficients of transverse dispersion $\mathrm{D}_{\mathrm{y}}$ can be determined based on practical dimensionless relations (11) and (12) for the range of coarse sands.

When determining the size of $\mathrm{D}_{\mathrm{y}}$ dispersion factors based on the dimensionless (11) and (12) relations in the following range of dimensionless products:

$$
\begin{gathered}
8,00 \leq \pi_{1} * 39,71 \\
0,65 \leq \pi_{1} * * 3,43 \\
0,02 \leq \pi_{2}^{*} \leq 0,43
\end{gathered}
$$

the error rates did not exceed $15 \%$.

The analysis of dimensionless relations for determining the size of $\mathrm{D}_{\mathrm{y}}$ transverse dispersion coefficients allows to determine the scope and amount of experimental investigations of the phenomenon of pollution spread in groundwater. It seems necessary for the further analysis of the conditions of modeling the spread of contaminants in groundwater to take into account cases of inhomogeneity and anisotropy of the soil medium, and to consider chemical and biological processes. 


\section{REFERENCES}

1. Acharya, RC, Valocchi, AJ, Werth, CJ and Willingham TW 2007. Pore-scale simulation of dispersion and reaction along a transverse mixing zone in twodimensional porous media. Water Resources Research 43, W10435.

2. Aniszewski, A 1981. Dyspersja poprzeczna zanieczyszczeń w strumieniu wody gruntowej [PhD thesis]. Szczecin: Politechnika Szczecińska.

3. Baron, T 1952. Generalized graphical method for the design of fixed bed catalytic reactors. Chemical Engineering progress 48,118-124.

4. Bijeljic, B and Blunt, MJ 2007. Pore-scale modelling of transverse dispersion in porous media. Water Resources Research 43, W12S11.

5. Canter, LW and Knox, RC 1986. Ground water pollution control. Michigan: Lewis Publishers, INC.

6. Ranz WE 1952. Friction and transfer coefficients for single particles and packed beds. Chemical Engineering progress 48, 247-253.

7. Saffman, PG 1959. A theory of dispersion in a porous medium. Journal Fluid Mechanics 6, 194-208.

8. Scheidegger, AE 1961. General theory of dispersion in porous media. Journal Geophysical Research 66, 3273-3278.

9. Sawicki, JM 2003. Migracja zanieczyszczeń. Gdańsk: Wydawnictwo Politechniki Gdańskiej.

10. Sielski, J 1972. Hydraulika. Ruch wody w gruncie. Gdańsk: Politechnika Gdańska.

\section{WARUNKI MODELOWANIA FIZYCZNEGO ROZPRZESTRZENIANIA ZANIECZYSZCZEŃ W WODZIE GRUNTOWEJ}

\section{Streszczenie}

Praca zawiera przegląd bezwymiarowych zależności doświadczalnych określających współczynnik poprzecznej dyspersji Dy. W toku analizy wymiarowej zestawiono bezwymiarowe zależności doświadczalne opisujące rozprzestrzenianie zanieczyszczeń $\mathrm{w}$ wodzie gruntowej z parametrami hydraulicznymi i fizycznymi gruntu w przypadku ustalonego i jednostajnego ruchu wody gruntowej. Analiza pozwoliła na określenie bezwymiarowych zależności praktycznych określających współczynnik dyspersji w kierunku prostopadłym do głównego kierunku przepływu.

Słowa kluczowe: $\quad$ zanieczyszczenia, woda gruntowa, współczynnik dyspersji

Editor received the manuscript: 11.12 .2018 